\title{
Collaborative Mixed Reality Games
}

Sultan A. Alharthi

Play \& Interactive Experiences

for Learning Lab

Dept. Computer Science

New Mexico State University

Las Cruces, NM, USA

salharth@nmsu.edu

\section{Katta Spiel}

$\mathrm{HCl}$ Group, TU Wien

Vienna, Austria \&

$\mathrm{HCl}$ Games Group

University of Waterloo

Waterloo, ON, Canada

katta@igw.tuwien.ac.at

William A. Hamilton

Dept. Computer Science

New Mexico State University

Las Cruces, NM, USA

bilhamil@nmsu.edu
Elizabeth Bonsignore

Human-Computer Interaction

Lab (HCIL)

College of Information Studies

University of Maryland

College Park, MD, USA

ebonsign@umd.edu

Zachary O. Toups

Play \& Interactive Experiences

for Learning Lab

Dept. Computer Science

New Mexico State University

Las Cruces, NM, USA

z@cs.nmsu.edu

Permission to make digital or hard copies of part or all of this work for personal or classroom use is granted without fee provided that copies are not made or distributed for profit or commercial advantage and that copies bear this notice and the full citation on the first page. Copyrights for third-party components of this work must be honored For all other uses, contact the owner/author(s).

Copyright held by the owner/author(s).

CSCW'18 Companion, November 3-7, 2018, Jersey City, NJ, USA ACM 978-1-4503-6018-0/18/11.

https://doi.org/10.1145/3272973.3273013

\begin{abstract}
Collaborative mixed reality games enable shared social experiences, in which players interact with the physical and virtual game environment, and with other players in real-time. Recent advances in technology open a range of opportunities for designing new and innovative collaborative mixed reality games, but also raise questions around design, technical requirements, immersion, safety, and player experience. This workshop seeks to bring together researchers, designers, practitioners, and players to identify the most pressing challenges that need to be addressed in the next decade, discuss opportunities to overcome these challenges, and highlight lessons learned from past designs of such games. Participants will present their ideas, assemble and discuss a collection of related papers, outline a unifying research agenda, and engage in an outdoor game ideation and prototyping session. We anticipate that the CSCW community can contribute to designing the next generation of collaborative mixed reality games and technologies and to support the growth of research and development in this exciting and emerging area.
\end{abstract}

\section{Author Keywords}

Collaboration, mixed reality, augmented reality, locationbased, games, social games, CSCW, workshop. 


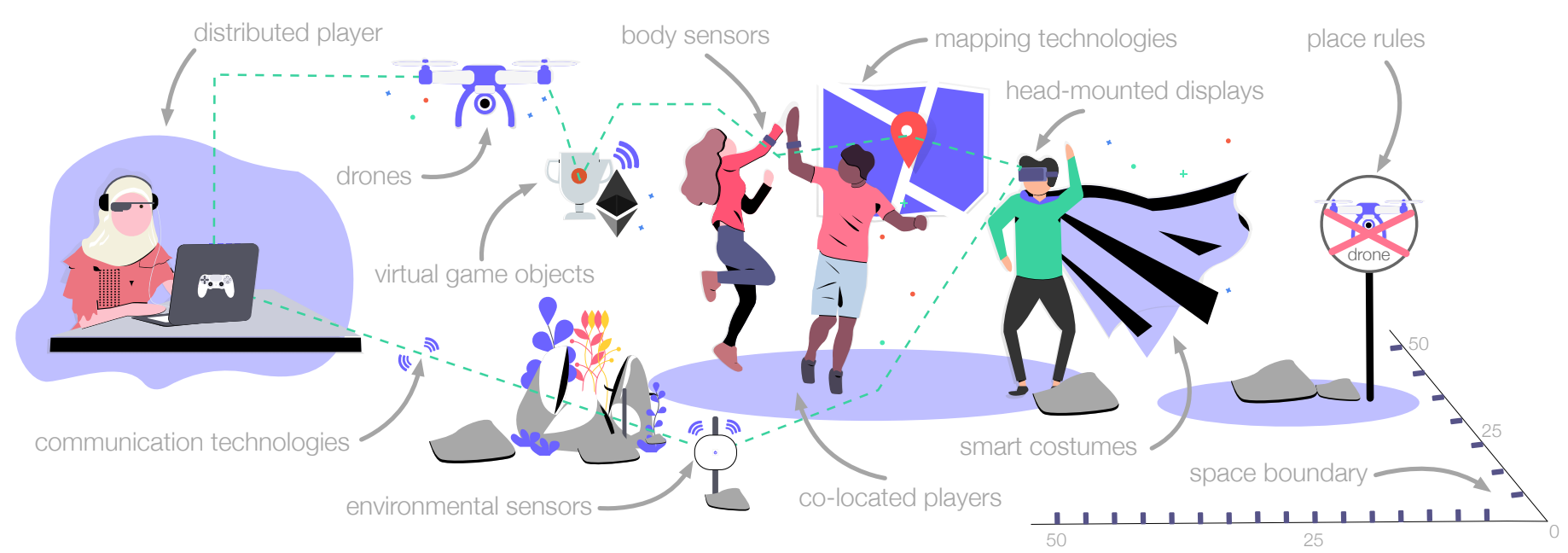

Figure 1: One vision of a collaborative mixed reality game setup illustrates the need for a composition of different technologies and designs. Enabling both co-located and distributed play, using body and environmental sensors [2], designing wearable technologies [25, 27], supporting communication and mapping [17], incorporating latest trends (e.g., drones) [16], selecting spaces and making places for play [24], and adhering to public and social rules [23]. (@) All figures used to create this illustration were obtained with permission from https://undraw.co.)

\section{Introduction}

Mixed reality combines virtual information with a physical reality experience that takes place in physical environments [18]. Collaborative mixed reality games enable shared social experiences, in which players interact with the physical and virtual game environment, and with other players in real-time [2, 4, 24]. Such social games enable different interaction modes, in which players engage with combinations of co-located physical environments, remote virtual environments, and players, both co-located and remote, to complete game objectives (Figure 1). Designers of such games do not need to simulate a physical game environment, they simply use an existing one (e.g., outdoor playground). The physical environment affords and constrains actions in the game through a combination of layout, size, available technology, rules, and social contracts $[23,24]$. Such sophisticated collaborative systems are not easy to build; rather, they require considerable effort including designing virtual game elements, selecting suitable technologies, defining indoor/outdoor boundaries of play, and ensuring player safety.

Recent advances in technology open a range of opportunities for designing new and innovative collaborative mixed reality games. For example, the use of wearable sensors (e.g., fitness trackers) can track players' physiological data [2], head-mounted displays (HMDs, e.g., Microsoft HoloLens) can display virtual game objects and enable team awareness [10,29], unmanned aerial vehicles (i.e., drones) can 
be used to explore futuristic scenarios and enable remote sensing [14-16], and mapping technologies (e.g., Google Maps) enable location tracking [20].

Due to these advances in technology, new types of games have proliferated, such as location-based games (e.g., Pokemon GO [20]), spatial mixed reality play [24], alternate reality games [5, 13, 18], live action role-playing games [2], costume play-cosplay [27], and exergames [19]. However, this proliferation raises a number of questions around design approaches, technical requirements, immersion, safety, and player experience $[2,23,24]$.

A major design challenge in this domain is to be able to combine multiple technologies, such as body sensors, HMDs or mapping solutions, in a way they can work together in harmony, ensure the safety of players in the outdoors, and enable fun and engaging collaborative experiences. One approach to overcome some of these challenges is to understand players' and teams' behaviors in these collaborative games, how these games transform existing technologies [9], relationships [6, 21, 22, 26], learning [6,7], spaces and places [23,24], and team dynamics $[2,11,12]$. Such an understanding has the potential to provide insights into the design of collaborative mixed reality games that work well.

Drawing on our interdisciplinary and collective experiences developing and studying a variety of collaborative and mixed reality games [1-3, 5-8, 15, 24, 29], we see an opportunity to gain valuable insights from researchers, developers, and players on the challenges, opportunities, and lessons learned through the design of collaborative mixed reality games. We assert that a cohesive research agenda is needed to further develop this field, which is currently lacking within the respectively interested research communities. This workshop serves as a bridge between members of the
CSCW, $\mathrm{HCl}$, and games community to encourage further studies and collaboration in understanding and designing the next generation of collaborative mixed reality games.

\section{Workshop Goals and Themes}

Drawing on the success of the previous mixed reality games workshop at CSCW '12 [8], we continue to examine how to support research, design, and development of collaborative mixed reality games. The goal of this workshop is to bring together individuals interested in collaborative mixed reality games to build a unifying research agenda, share ongoing work in the area, engage in group ideation and prototyping, and encourage collaboration. We invite proposals from academic and industry researchers that focus on these themes:

- Player Experience/Spectator Experience: what are the contextual social parameters and relationships that take place in these collaborative games and how to understand them, including place attachment, placemaking, social ties between players, and understanding of players and spectators experience and behavior in such games;

- Safety \& Ethics: what are the ethical challenges that come with these collaborative mixed reality games and how can we overcome them, including social rules and norms as well as public safety;

- Technology: how can new interaction technologies be designed, integrated, and used in such games, including wearable devices, body and environmental sensors, communication modalities, location tracking, GIS and mapping technologies to support indoor/outdoor collaborative play experiences; and 


\section{Planned Activities \& Schedule}

09:00-09:30: Workshop opening by organizers.

09:30-11:00: Introductions and presentations by participants.

11:00-12:00: Round-table discussion session.

12:00-13:30: Lunchbreak.

13:30-15:30: Outdoor game ideation and prototyping session.

15:30-16:30: Short presentations of main observations from the game ideation and prototyping session.

16:30-17:00: Future directions session.

18:30: Dinner (optional).
- Design: what are the methods and guidelines that can support designers and developers of collaborative mixed reality play and games, including design frameworks and game design patterns.

We are also interested in alternative perspectives on collaborative mixed reality games and encourage submissions on research that the authors plan to conduct, which can benefit from feedback in between the workshop sessions.

\section{Workshop Format and Activities}

This is a one-day workshop for up to 25 participants that will be organized in 4 sessions. Before we enter the structured programme, we will open the workshop by introducing the workshop organizers, and explain the planned activities and schedule.

Participant Presentations. Workshop participants will be invited to give a short presentation on their ideas and research that broadly address the main workshop themes. This session will help establish a sense of the existing work, and highlight the different perspectives on collaborative mixed reality games.

Round-table Discussion. In the session, participants will split into small groups for a round-table discussion to summarize key challenges, open questions, and future opportunities for the design of collaborative mixed reality games. Each group will assemble a collection of related papers, based on their own experience with the literature, and outline a research agenda that have the potential to support the growth of research and development of collaborative mixed reality games in the CSCW community. One member of each group will then present the key research areas the group identified that need further investigation in an openfloor discussion with the rest of the workshop participants.
Outdoor Game Ideation and Prototyping Session. This session will enable participants to undertake hands-on, outdoor, group activity to create a collaborative mixed reality game idea. Following the workshop main themes, each group will discuss what experiences they want for their potential players, select outdoor spaces for their mixed reality game [24], identify the affordances and constraints of their selected space, what safety measures are needed, and what technologies need to be available for the intended experience to take place. The design activities are framed and loosely structured following the concept of future technology workshops [28]. Each group will then create a paper-based prototype of their game design idea (a range of prototyping materials will be provided by the organizers). At the conclusion of the prototyping session, each group will discuss their idea, observations, challenges, and opportunities for the design of future collaborative mixed reality games.

Future Directions Finally, based on the participants presentations, round-table discussion, and game ideation and prototyping session, a long-term research agenda will be out-lined and discussed that highlights future directions in collaborative mixed reality games. The research agenda will be published on the website as the results of this workshop.

\section{Participant Recruitment and Selection}

Workshop papers should be 2-4 pages in SIGCHI Extended Abstract format and submitted to workshop organizers by September 30, 2018. The workshop website includes the paper requirements, submission date, and selection process https://collaborativemr.wordpress.com.

Submissions should be sent to the workshop email: collaborativemr@gmail.com. Accepted papers will require that at least one presenting author registers for the workshop. Workshop results and accepted papers will be made publicly available on the workshop website. 


\section{Organizing Team}

Sultan A. Alharthi is a PhD student in the Department of Computer Science at New Mexico State University and currently a User Interface Research Intern at Autodesk Research, Toronto, Canada. Sultan works primarily at the intersection of human-computer interaction, computersupported cooperative work, and mixed reality. He researches and develops new and innovative collaborative and mixed reality games and systems to support team play, awareness, sensemaking, and planning.

Katta Spiel is a PhD candidate at TU Wien and currently a Visiting Researcher at the University of Waterloo. Katta has a background in Cultural Studies and Computer Science from Bauhaus-Universität Weimar. Their research focuses on the empowering design of technologies and artifacts with and for marginalised people. Other research interests include games and play, queer disability studies, and philosophy of science.

William A. Hamilton is an Assistant Professor in the Department of Computer Science at New Mexico State University. Dr. Hamilton's work primarily investigates how media impacts participation, understanding video game live streaming, and how to support participation and collaboration in the situated contexts of education and games.

Elizabeth (Beth) Bonsignore is an Assistant Research Scientist at the University of Maryland's Human-Computer Interaction Lab (HCIL) and College of Information Studies (Maryland's iSchool). Her research focuses on the design of technology-mediated social experiences that promote new media literacies, arts-integrated science learning, shared storytelling, and participatory cultures for youth. This work involves close co-design partnerships with children and teens (7-17 years old), which led to her appoint- ment as Director of Kidsteam, an intergenerational team of children and adults who collaborate to design new technologies for children. She has contributed to US NSF-funded projects on the design of alternate reality games and mobile storytelling.

Zachary O. Toups is an Associate Professor in the Department of Computer Science at New Mexico State University. Dr. Toups' research focuses on computer-supported cooperative play and the physical-world contexts that it can support. From a human-centered approach, he develops and researches mixed reality computing that engages players in human-human, human-environment, and human-computer interaction and investigates new collaborative technologies that support disaster response training.

\section{Acknowledgments}

This material is based upon work supported by the National Science Foundation under Grant Nos. IIS-1651532 and IIS-1619273. Any opinions, findings, conclusions, or recommendations expressed in this material are those of the authors and do not necessarily reflect the views of the $\mathrm{Na}$ tional Science Foundation.

\section{REFERENCES}

1. Sultan A. Alharthi, Nick LaLone, Ahmed S. Khalaf, Ruth Torres, Lennart Nacke, Igor Dolgov, and Zachary O.

Toups. 2018a. Practical Insights into the Design of Future Disaster Response Training Simulations. In ISCRAM 2018 Conference Proceedings - 15th International Conference on Information Systems for Crisis Response and Management, Kees Boersma and Brian Tomaszeski (Eds.). 818-830.

2. Sultan A. Alharthi, Hitesh Nidhi Sharma, Sachin Sunka, Igor Dolgov, and Zachary O. Toups. 2018b. Designing Future Disaster Response Team Wearables from a 
Grounding in Practice. In Proceedings of the Technology, Mind, and Society (TechMindSociety '18). ACM, Article 1, 6 pages. DOI : http://dx.doi.org/10.1145/3183654.3183662

3. Sultan A. Alharthi, Ruth C. Torres, Ahmed S. Khalaf, Zachary O. Toups, Igor Dolgov, and Lennart E. Nacke. 2018c. Investigating the Impact of Annotation Interfaces on Player Performance in Distributed Multiplayer Games. In Proceedings of the $2018 \mathrm{CHI}$ Conference on Human Factors in Computing Systems (CHI '18). ACM, New York, NY, USA, Article 314, 13 pages. DOI:

http://dx.doi.org/10.1145/3173574.3173888

4. Mark Billinghurst and Hirokazu Kato. 1999. Collaborative mixed reality. In Proceedings of the First International Symposium on Mixed Reality. 261-284.

5. Elizabeth Bonsignore, Derek Hansen, Kari Kraus, June Ahn, Amanda Visconti, Ann Fraistat, and Allison Druin. 2012. Alternate Reality Games: platforms for collaborative learning. In Proceedings of the 10th International Conference of the Learning Sciences (ICLS 2012), Vol. 1. 251-258.

6. Elizabeth Bonsignore, Derek Hansen, Kari Kraus, Amanda Visconti, and Ann Fraistat. 2016a. Roles People Play: Key Roles Designed to Promote Participation and Learning in Alternate Reality Games. In Proceedings of the 2016 Annual Symposium on Computer-Human Interaction in Play (CHI PLAY '16). ACM, New York, NY, USA, 78-90. DOI :

http://dx.doi.org/10.1145/2967934.2968108

7. Elizabeth Bonsignore, Derek Hansen, Anthony Pellicone, June Ahn, Kari Kraus, Steven Shumway,
Kathryn Kaczmarek, Jeff Parkin, Jared Cardon, Jeff Sheets, Carlea Holl-Jensen, and Jes Koepfler. 2016b. Traversing Transmedia Together: Co-designing an Educational Alternate Reality Game For Teens, With Teens. In Proceedings of the The 15th International Conference on Interaction Design and Children (IDC '16). ACM, New York, NY, USA, 11-24. DOI : http://dx.doi.org/10.1145/2930674.2930712

8. Elizabeth M. Bonsignore, Derek L. Hansen, Zachary O. Toups, Lennart E. Nacke, Anastasia Salter, and Wayne Lutters. 2012. Mixed Reality Games. In Proceedings of the ACM 2012 Conference on Computer Supported Cooperative Work Companion (CSCW '12). ACM, 7-8. DOI : http://dx.doi.org/10.1145/2141512.2141517

9. Joseph A. Gonzales, Casey Fiesler, and Amy Bruckman. 2015. Towards an Appropriable CSCW Tool Ecology: Lessons from the Greatest International Scavenger Hunt the World Has Ever Seen. In Proceedings of the 18th ACM Conference on Computer Supported Cooperative Work \&\#38; Social Computing (CSCW '15). ACM, New York, NY, USA, 946-957. DOI : http://dx.doi.org/10.1145/2675133.2675240

10. Sebastian Günther, Florian Müller, Martin Schmitz, Jan Riemann, Niloofar Dezfuli, Markus Funk, Dominik Schön, and Max Mühlhäuser. 2018. CheckMate: Exploring a Tangible Augmented Reality Interface for Remote Interaction. In Extended Abstracts of the 2018 $\mathrm{CHI}$ Conference on Human Factors in Computing Systems (CHI EA '18). ACM, New York, NY, USA, Article LBW570, 6 pages. DOI :

http://dx.doi.org/10.1145/3170427.3188647 
11. David Gurzick, Brian Landry, and Kevin F. White. 2010. Alternate Reality Games and Groupwork. In Proceedings of the 16th ACM International Conference on Supporting Group Work (GROUP '10). ACM, New York, NY, USA, 303-304. DOI : http://dx.doi.org/10.1145/1880071.1880121

12. David Gurzick, Kevin F. White, Wayne G. Lutters, Brian M. Landry, Caroline Dombrowski, and Jeffery Y. Kim. 2011. Designing the Future of Collaborative Workplace Systems: Lessons Learned from a Comparison with Alternate Reality Games. In Proceedings of the 2011 iConference (iConference '11). ACM, New York, NY, USA, 174-180. DOI : http://dx.doi.org/10.1145/1940761.1940785

13. Ke Jing, Natalie Nygaard, and Joshua Tanenbaum. 2017. Magia Transformo: Designing for Mixed Reality Transformative Play. In Extended Abstracts Publication of the Annual Symposium on Computer-Human Interaction in Play (CHI PLAY '17 Extended Abstracts). ACM, New York, NY, USA, 421-429. DOI : http://dx.doi.org/10.1145/3130859.3131339

14. Brennan Jones, Kody Dillman, Richard Tang, Anthony Tang, Ehud Sharlin, Lora Oehlberg, Carman Neustaedter, and Scott Bateman. 2016. Elevating Communication, Collaboration, and Shared Experiences in Mobile Video Through Drones. In Proceedings of the 2016 ACM Conference on Designing Interactive Systems (DIS '16). ACM, New York, NY, USA, 1123-1135. DOI : http://dx.doi.org/10.1145/2901790.2901847

15. Ahmed S. Khalaf, Poom Pianpak, Sultan A. Alharthi, Zahra NaminiMianji, Ruth Torres, Son Tran, Igor Dolgov, and Zachary O. Toups. 2018. An Architecture for Simulating Drones in Mixed Reality Games to Explore Future Search and Rescue Scenarios. In In Proceedings of the 15th International Conference on Information Systems for Crisis Response and Management.

16. Heesoon Kim and James A. Landay. 2018. Aeroquake: Drone Augmented Dance. In Proceedings of the 2018 Designing Interactive Systems Conference (DIS '18). ACM, New York, NY, USA, 691-701. DOI : http://dx.doi.org/10.1145/3196709.3196798

17. Sebastian Matyas, Christian Matyas, Christoph Schlieder, Peter Kiefer, Hiroko Mitarai, and Maiko Kamata. 2008. Designing Location-based Mobile Games with a Purpose: Collecting Geospatial Data with CityExplorer. In Proceedings of the 2008 International Conference on Advances in Computer Entertainment Technology (ACE '08). ACM, New York, NY, USA, 244-247. DOI :

http://dx.doi.org/10.1145/1501750.1501806

18. Markus Montola. 2011. A Ludological View on the Pervasive Mixed-reality Game Research Paradigm. Personal Ubiquitous Comput. 15, 1 (Jan. 2011), 3-12. DOI : http://dx. doi .org/10.1007/s00779-010-0307-7

19. Florian 'Floyd' Mueller and Matthew Muirhead. 2015. Jogging with a Quadcopter. In Proceedings of the 33rd Annual ACM Conference on Human Factors in Computing Systems (CHI '15). ACM, New York, NY, USA, 2023-2032. DOI : http://dx.doi.org/10.1145/2702123.2702472

20. Niantic, Inc. 2016. Pokèmon GO. Game [Mobile]. (06 July 2016). Niantic, Inc., San Francisco, CA, USA. 
21. Kenton O'Hara, Hazel Grian, and John Williams. 2008. Participation, Collaboration and Spectatorship in an Alternate Reality Game. In Proceedings of the 20th Australasian Conference on Computer-Human Interaction: Designing for Habitus and Habitat (OZCHI '08). ACM, New York, NY, USA, 130-139. DOI : http://dx.doi.org/10.1145/1517744.1517787

22. Stuart Reeves. 2011. Designing Interfaces in Public Settings: Understanding the Role of the Spectator in Human-Computer Interaction (1st ed.). Springer Publishing Company, Incorporated.

23. Pavel Andreevich Samsonov, Xun Tang, Johannes Schöning, Werner Kuhn, and Brent Hecht. 2015. You Can'T Smoke Here: Towards Support for Space Usage Rules in Location-aware Technologies. In Proceedings of the 33rd Annual ACM Conference on Human Factors in Computing Systems (CHI '15). ACM, New York, NY, USA, 971-974. DOI :

http://dx.doi.org/10.1145/2702123.2702269

24. Hitesh Nidhi Sharma, Sultan A. Alharthi, Igor Dolgov, and Zachary O. Toups. 2017. A Framework Supporting Selecting Space to Make Place in Spatial Mixed Reality Play. In Proceedings of the Annual Symposium on Computer-Human Interaction in Play (CHI PLAY '17). ACM, 83-100. DOI :

http://dx.doi.org/10.1145/3116595.3116612

25. Hitesh Nidhi Sharma, Zachary O. Toups, Igor Dolgov, Andruid Kerne, and Ajit Jain. 2016. Evaluating Display Modalities Using a Mixed Reality Game. In Proceedings of the 2016 Annual Symposium on Computer-Human Interaction in Play (CHI PLAY '16).
ACM, New York, NY, USA, 65-77. DOI :

http://dx.doi.org/10.1145/2967934.2968090

26. Cynthia M. Sifonis. 2017. Attributes of Ingress Gaming Locations Contributing to Players' Place Attachment. In Extended Abstracts Publication of the Annual Symposium on Computer-Human Interaction in Play (CHI PLAY' 17 Extended Abstracts). ACM, New York, NY, USA, 569-575. DOI : http://dx.doi.org/10.1145/3130859.3131338

27. Joshua Tanenbaum, Karen Tanenbaum, Katherine Isbister, Kaho Abe, Anne Sullivan, and Luigi Anzivino. 2015. Costumes and Wearables As Game Controllers. In Proceedings of the Ninth International Conference on Tangible, Embedded, and Embodied Interaction (TEI '15). ACM, New York, NY, USA, 477-480. DOI : http://dx.doi.org/10.1145/2677199.2683584

28. Giasemi Vavoula and Mike Sharples. 2007. Future technology workshop: A collaborative method for the design of new learning technologies and activities. International Journal of Computer-Supported Collaborative Learning 2, 4 (2007), 393-419. DOI : http://dx.doi.org/10.1007/s11412-007-9026-0

29. Jason Wuertz, Sultan A. Alharthi, William A. Hamilton, Scott Bateman, Carl Gutwin, Anthony Tang, Zachary Toups, and Jessica Hammer. 2018. A Design Framework for Awareness Cues in Distributed Multiplayer Games. In Proceedings of the $2018 \mathrm{CHI}$ Conference on Human Factors in Computing Systems (CHI '18). ACM, New York, NY, USA, Article 243, 14 pages. DOI :

http://dx.doi.org/10.1145/3173574.3173817 